\title{
Passivation of Steel and Stainless Steel in Alkaline Media Simulating Concrete
}

Bernhard Elsener ${ }^{1), 2)}$ and Antonella Rossi ${ }^{1), 3)}$

1) Dipartimento di Scienze Chimiche e Geologiche, Università degli Studi di Cagliari, Cittadella Universitaria di Monserrato, I - 09100 Cagliari, Italy

2) ETH Zurich, Institute for Building Materials, Zurich (Switzerland)

3) ETH Zurich, Laboratory for Surface Science and Technology, Department of Materials, Vladimir-Prelog-Weg 5, CH-8093 Zurich, Switzerland

\begin{abstract}
The presence of the protective oxide film (passive film) is the basis for the durability of reinforced concrete structures. The formation of the passive film in the alkaline environment of concrete occurs spontaneously, it is influenced by the $\mathrm{pH}$ and the composition of the pore solution of concrete. In this work results from electrochemical and surface analytical studies are presented and discussed. It is found that the passive film becomes more stable with prolonged immersion (ageing), this is reflected in a decreasing passive current density, an increasing open circuit potential and a decrease in the Fe(II) ions acting as defects in the passive film. Compiling the available data the decrease in passive current density can be related to the decrease in the $\mathrm{Fe}(\mathrm{II})$ concentration in the passive film. On $\mathrm{FeCr}$ alloys and stainless steels similar trends have been reported. The stability of the passive film against localized chloride induced corrosion is briefly discussed. Ageing of the passive film has been found to increase the pitting potential. Alloying with chromium and molybdenum increases the pitting resistance of stainless steels, special emphasis is given to the composition of the alloy interface beneath the passive film and its enrichment in nickel.
\end{abstract}




\section{Introduction}

During hydration of Portland cement (OPC) a highly alkaline pore solution is obtained. In this environment the thermodynamically stable compounds of iron and iron based alloys are oxides and hydroxides. Thus on reinforcing steel embedded in alkaline concrete a thin protective oxide layer (the passive film) is spontaneously formed [1,2]. This is the main reason for the widespread use of reinforced and pre-stressed concrete in construction industry worldwide. In a recent review on the steel - concrete interface (SCI), the steel surface and specifically the passive film has been identified as one of the crucial issues for the durability of reinforced concrete structures [3]. The wording "passivation of reinforcing steel in concrete" however is very broad as both, the steel and the pore solution in concrete, may have variable composition [3].

Pore solution is defined as the alkaline solution present in the pores of hardened concrete. The $\mathrm{pH}$ of this solution in Ordinary Portland Cement (OPC) is in the range from $13-13.8$ due to the dissolution of the variable amount of $\mathrm{Na}_{2} \mathrm{O}$ and $\mathrm{K}_{2} \mathrm{O}$ present in the different cements $[2$, 4]. Portlandite, $\mathrm{Ca}(\mathrm{OH})_{2}$, is formed during the reaction of the cement with mixing water and is present as solid product in the cement paste as alkali reserve, dissolved in the pore solution it maintains a $\mathrm{pH}$ at 12.5. The formation of a passive films on iron and stainless steels in alkaline environments simulating concrete has been mainly investigated in saturated $\mathrm{Ca}(\mathrm{OH})_{2}$ ( $\mathrm{pH} 12.5)$ or in $\mathrm{NaOH}$ or $\mathrm{KOH}$ solutions at different concentrations and $\mathrm{pH}$.

The reinforcing steel, despite similar chemical composition, can show different metallurgical structure due to different hardening processes (cold worked or quenched and tempered) resulting in different corrosion behaviour $[3,5]$. In practice the steel is covered by mill scale or even rust [3] when the concrete is put in place, showing a broad distribution of the local open circuit potential measured [6] reflecting the different surface states. In most laboratory studies the steel was not used in this "as received" condition but the surface was mechanically polished, grinded or sandblasted in order to get a reproducible starting point [3]. Note that also "mechanically polished" surfaces may vary in surface composition (polishing media, fineness, time of air exposure before immersion in solution etc.). 
Studies on passivation of black steel and stainless steels in alkaline environments are mainly based on electrochemical techniques [see ref. 3 and literature cited therein]. From passivation experiments under controlled oxidation conditions (applying a constant anodic potential) it was concluded that the passive film can be described as a double-layered structure with an internal oxide film acting as barrier layer and an external oxy-hydroxide layer in contact with the solution. The electrochemical response of this passive layer is controlled by the $\mathrm{pH}$ of the solution and the potential of formation of the passive film [2 - 4].

In this work electrochemical and surface analytical results on the passive film formation and composition of iron, Fe-15 Cr alloy and different stainless steels are reported and discussed in the context of mechanistic models of the passive film formation in literature. The importance of the alloy interface beneath the passive film for the protective properties of the passive film on stainless steels is highlighted.

\section{Spontaneous passivation in alkaline solutions}

Spontaneous passivation of steel in alkaline media has been investigated following the open circuit potential (OCP) and the polarization resistance Rp over time, in some work also thickness and composition of the surface film was measured. Literature work agrees for black steel and stainless steel on an asymptotical increase of both parameters, OCP [5 - 16] and Rp upon time $[6,10,13,14]$ indicating the formation of a protective oxide film (the passive film).

\section{Open circuit potentials}

Results of the OCP vs time curve measured for $24 \mathrm{~h}$ on three different iron based alloys ( $\mathrm{Fe} 15 \mathrm{Cr}, \mathrm{Fe} 18 \mathrm{Cr} 8 \mathrm{Ni}$ and $\mathrm{Fe} 22 \mathrm{Cr} 6 \mathrm{Ni} 2 \mathrm{Mo}$ ) mechanically polished in synthetic pore solution, in $0.1 \mathrm{M} \mathrm{NaOH}$ and in sat. $\mathrm{Ca}(\mathrm{OH})_{2}+0.1 \mathrm{M} \mathrm{NaOH}$, are shown in Figure 1. 

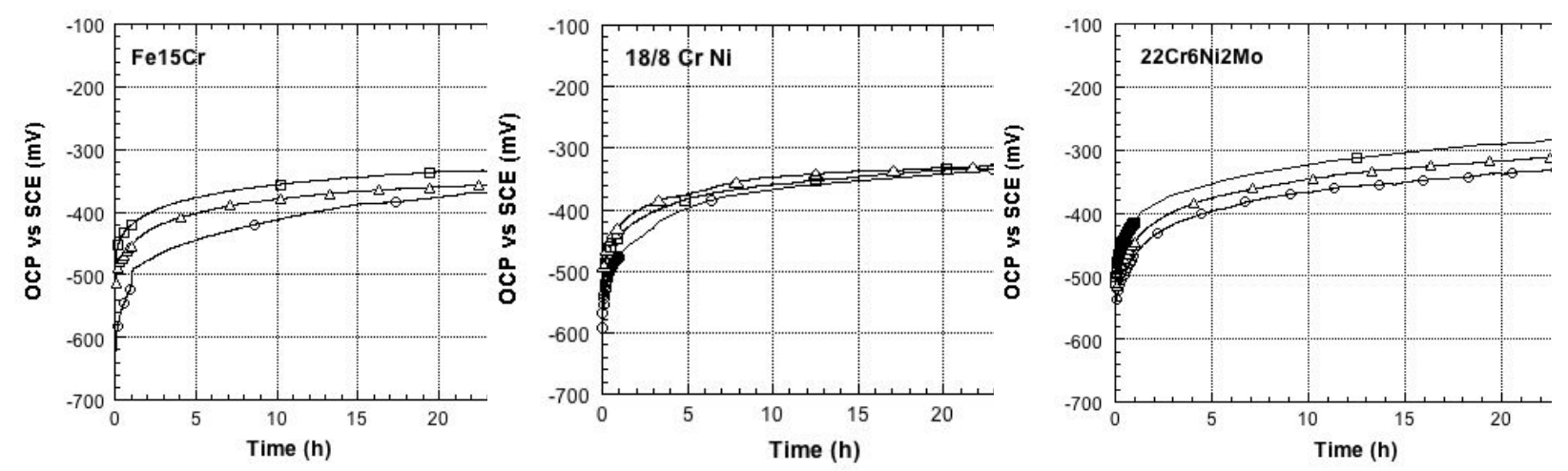

Figure 1: OCP versus time for $\mathrm{Fe} 15 \mathrm{Cr}, \mathrm{Fe} 18 \mathrm{Cr} 8 \mathrm{Ni}$ and $\mathrm{Fe} 22 \mathrm{Cr} 6 \mathrm{Ni} 2 \mathrm{Mo}$ alloys in de-aerated solutions of saturated $\mathrm{Ca}(\mathrm{OH})_{2}+0.1 \mathrm{M} \mathrm{NaOH}, 0.1 \mathrm{M} \mathrm{NaOH}$ and synthetic pore solution. Data from [17].

On the nine different systems (alloys and solutions) studied the OCP starts at negative values around $-500 \mathrm{mV} \mathrm{SCE}$, increases rapidly in the first hour and then tends asymptotically towards an end value of about $-300 \mathrm{mV}$ SCE (Figure 1). The same results were reported for the three alkaline solutions with $0.1 \mathrm{M} \mathrm{NaCl}$ added [17]. Literature results agree with these findings. The final value of the OCP reached depends on the duration of the experiment: after 1 day about $-350 \mathrm{mV} \mathrm{SCE}$ was reported for iron in $0.1 \mathrm{M} \mathrm{NaOH}[7,9]$, after five days -270 $\mathrm{mV}$ SCE was reported for iron in saturated $\mathrm{Ca}(\mathrm{OH})_{2}+0.2 \mathrm{M} \mathrm{KOH} \mathrm{[10]} \mathrm{and} \mathrm{after} 10$ days $220 \mathrm{mV}$ SCE for iron in different alkaline solutions [16]. Polished steel in sat. $\mathrm{Ca}(\mathrm{OH})_{2}$ solution ( $\mathrm{pH}$ 12.6) showed an initial OCP of about $-400 \mathrm{mV} \mathrm{SCE}$ that rapidly increased in the first 6 hours of immersion, interpreted as spontaneous growth of a protective oxide layer on the metal surface [14]. The potential continues to increase asymptotically for further six days. The final value is influenced by the $\mathrm{pH}$ of the solution and by the oxygen content in solution: samples immersed in Argon de-aerated solutions show more negative OCP values, solutions purged with oxygen much more positive ones up to $-170 \mathrm{mV} \mathrm{SCE}[7,9]$. The final value after six days immersion in sat. $\mathrm{Ca}(\mathrm{OH})_{2}$ was found at $-180 \pm 20 \mathrm{mV}$ SCE. Long time immersion (up to 100 days) of sandblasted steels in pore solution ( $\mathrm{pH}$ 13.6) showed OCP values between -200 to $-170 \mathrm{mV}$ SCE [6].

\section{Polarization resistance $R p$}

In addition to the evolution of OCP, linear polarization resistance (Rp) or electrochemical impedance spectroscopy (EIS), both with negligible perturbation around the OCP, were performed in order to get information on the corrosion rate and / or mechanism. Rp was 
generally found to increase with longer immersion time in a similar asymptotic manner as the OCP $[6,10,13,14]$ an example is shown in Figure 2. From EIS both the charge transfer resistance $R_{t}$ and film forming resistance $R_{f}$ were determined [10] both are increasing with prolonged immersion time (Fig. 2) whereas the associated capacitance was found to decrease.

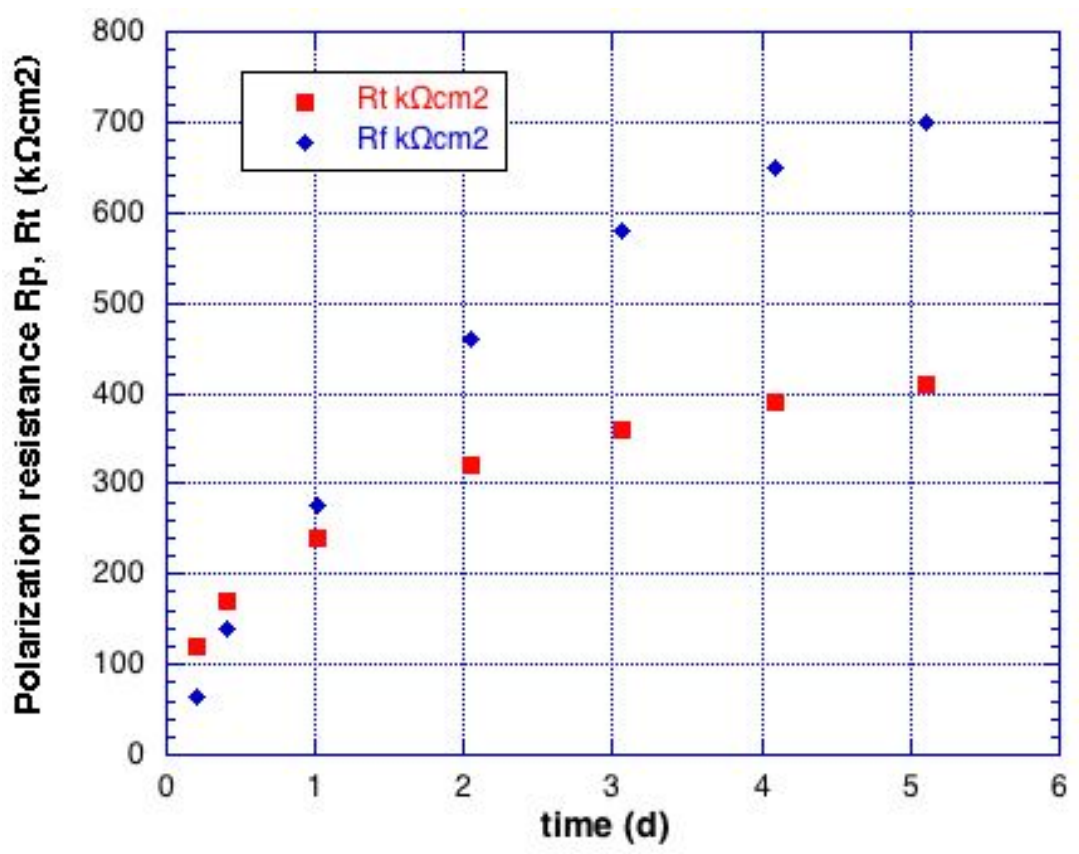

Figure 2: $\mathrm{R}_{\mathrm{t}}$ (charge transfer resistance) and $\mathrm{R}_{\mathrm{f}}$ (film forming resistance) vs OCP in solution $\mathrm{pH}$ 13.2. Data adapted from [10]

The open circuit potential and $R_{p}$ (also $R_{t}, R_{f}$ ) are not independent parameters but related with each other with electrochemical fundamentals (exponential equation of charge transfer reactions). This has been elaborated in detail, the resulting $\mathrm{i}_{\text {corr }}$ vs OCP plots obtained are shown in Fig. 3. Both $\mathrm{R}_{\mathrm{t}}$ and $\mathrm{R}_{\mathrm{f}}$ depend exponentially on the OCP showing a linear relation between $\log \mathrm{R}_{\mathrm{t}}$ and $\log \mathrm{R}_{\mathrm{f}}$ versus OCP. It is now interesting to note that the potential dependence (slope) is different for the two resistances, indicating a much stronger influence of potential on the film forming process. 


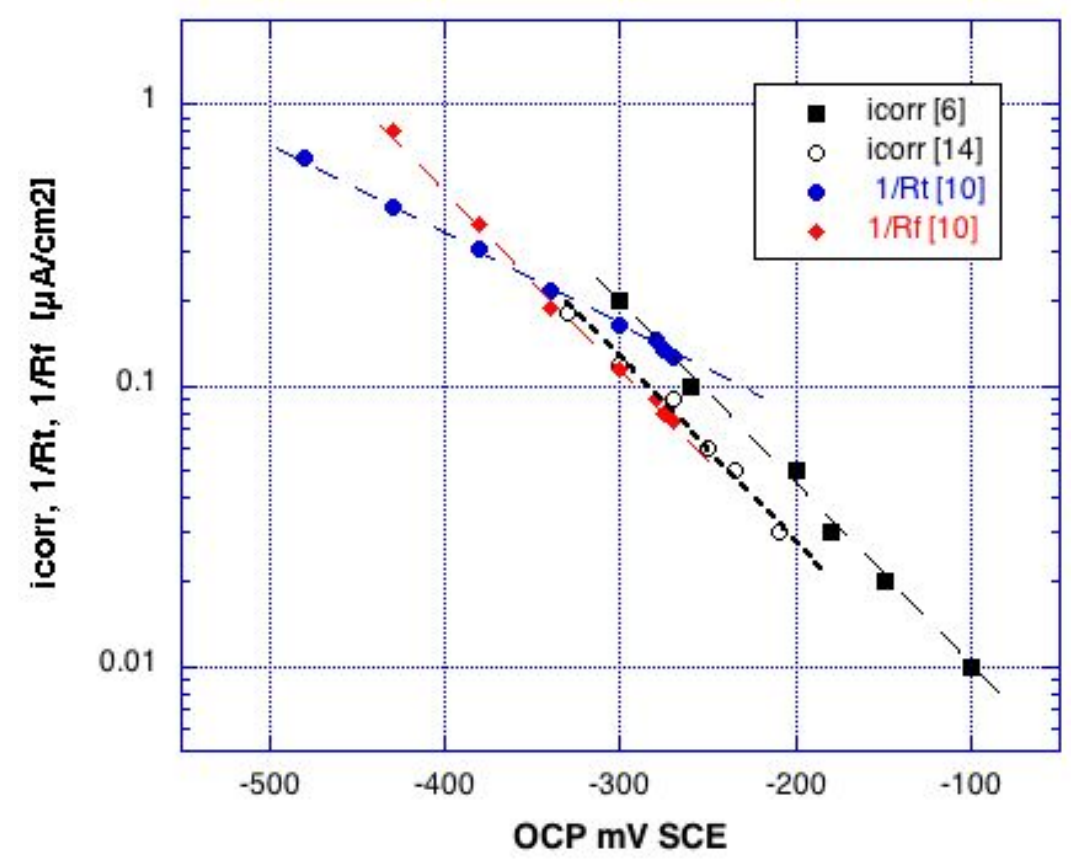

Figure 3: "Tafel plot" of corrosion, dissolution and film formation current versus OCP. Data from $[6,10,14]$.

When plotting the corrosion current density $\log i_{\text {corr }}[6,14]$ and $\log 1 / R_{t}$ and $\log 1 / R_{f}[10]$ versus OCP (Fig. 3) a linear behaviour is found that can be interpreted as cathodic polarization curve $\left(\log i_{c}\right.$ vs OCP). The Tafel's constant obtained for the plot $1 / R_{f}$ vs OCP is about $140 \mathrm{mV} / \mathrm{dec}$. In the paper of $\mathrm{Li}$ and Sagues [6] a similar relation between the corrosion rate $\mathrm{i}_{\text {corr }}$ (calculated from Rp measurements) and the open circuit potential was found. Despite some scatter in the original data, linear regression resulted in a slope of about $-145 \mathrm{mV}$. Also these authors interpreted the exponential behaviour as cathodic Tafel slope of the (activation controlled) oxygen evolution. The data [6] refer to much longer immersion times (up to 60 days), thus the OCP reached is more positive and the dissolution of the passive steel is in the order of less than $10 \mathrm{nA} / \mathrm{cm}^{2}$. Measurements in [6] were performed on sandblasted steel, thus the effective surface area (and $i_{\text {corr }}$ ) might be higher compared to a mechanically polished surface as used in other studies [10,14]. Data from polished steel exposed up to 6 days in sat. $\mathrm{Ca}(\mathrm{OH})_{2}$ solution [14] fit perfectly in the above picture.

It is now interesting to note that all the data coincide on one line, irrespective of the solution used (pH 12.6 in [14], $\mathrm{pH} 13.2$ in [10] and $\mathrm{pH} 13.6$ in [6]) or the time of immersion (5 days in [10], 6 days in [14] and up to 60 days in [6]). From Figure 3 it can be further concluded that the polarization resistance Rp obtained from LPR measurements $[6,14]$ corresponds to $R_{f}$ (film forming resistance) from the more detailed analysis of impedance measurements [10]. 


\section{Surface composition of the passive films}

Comparatively little is known about the surface chemistry of iron and stainless steels in alkaline media, i.e. on the analytical characterization of the passive film on their surface. A variety of surface analytical techniques have been applied to study the passive films formed in alkaline solutions. Early works based on ellipsometry [18, 19] and Raman spectroscopy [20] proposed for iron a multi-layer structure of the passive film with an inner layer of difficult-toreduce $\mathrm{Fe}_{3} \mathrm{O}_{4}$ and an outer gelatinous iron hydroxide layer. More recent work on iron in $0.1 \mathrm{M}$ $\mathrm{NaOH}[21,22]$ report a gradual oxidation of the oxide film changing from magnetite $\left(\mathrm{Fe}_{3} \mathrm{O}_{4}\right)$ to hematite $\left(\mathrm{Fe}_{2} \mathrm{O}_{3}\right)$ with increasing potential; this corresponds to a gradual decrease of the $\mathrm{Fe}(\mathrm{II})$ content in the passive film as determined by XPS surface analysis [23]. Similar results were reported on $\mathrm{FeCr}$ model alloys where $\mathrm{Cr}(\mathrm{III})$ oxy-hydroxides were found in the inner part of the passive film $[24,25]$.

\section{XPS surface analysis - determination of the chemical state}

X-ray photoelectron spectroscopy (XPS) is a powerful ex-situ technique to study thin oxide films in the range of few nanometre thickness on metallic surfaces. The principle and applications of this UHV technique are well documented [26]. Due to the interaction with the material, only photo-electrons from about $10-15 \mathrm{~nm}$ below the surface can escape to the UHV, this is the reason for the outstanding surface sensitivity of the XPS technique.
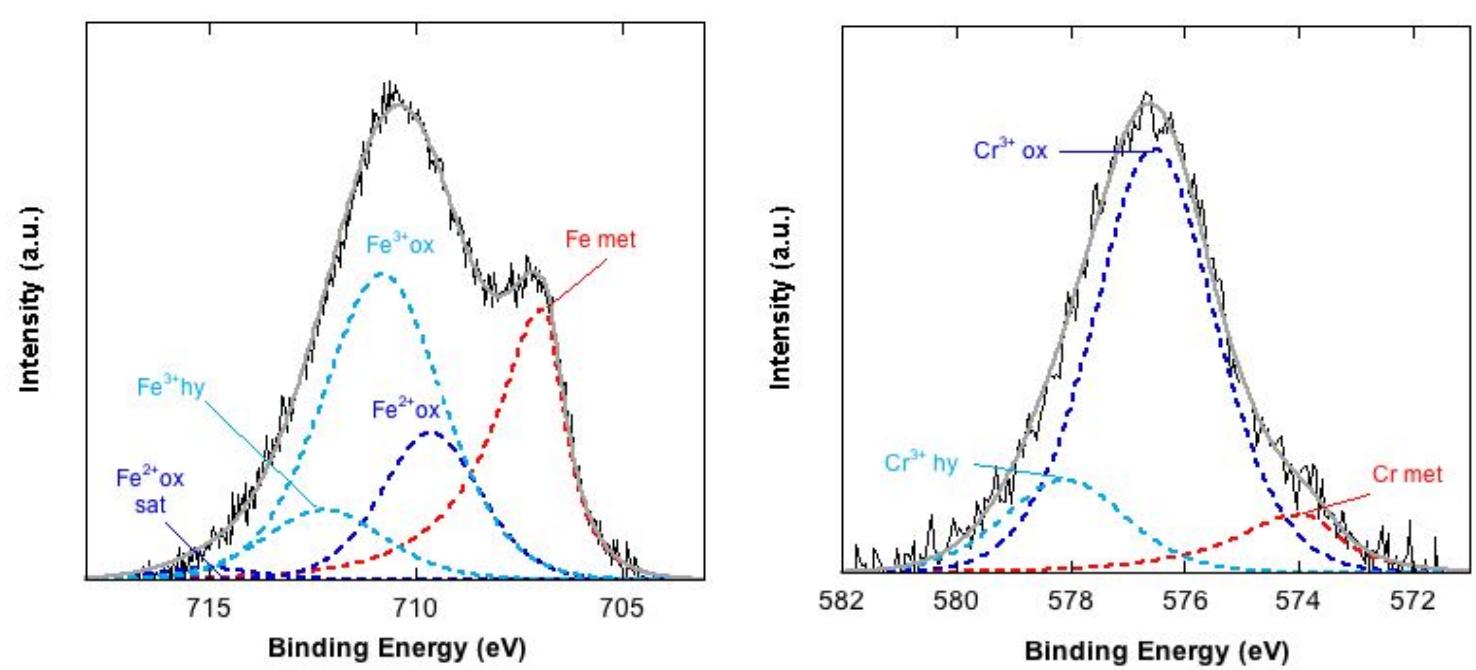

Figure 4: High-resolution spectra with curve fitting after background subtraction according to Shirley-Sherwood [27] of a) Fe2p3/2 signal and b) Cr2p3/2 signal (see text). Stainless steel $1.430115 \mathrm{~min}$ in $0.1 \mathrm{NaOH}$ (Data from [17]). 
XPS high-resolution spectra (Fig. 4) allow determining not only the elemental composition but the identification of the chemical state, e.g. to differentiate between metallic iron, iron(II)oxide and iron(III)oxide or hydroxide (Fig. 4a). The following species with their respective binding energies measured at the peak centre of gravity have been identified:

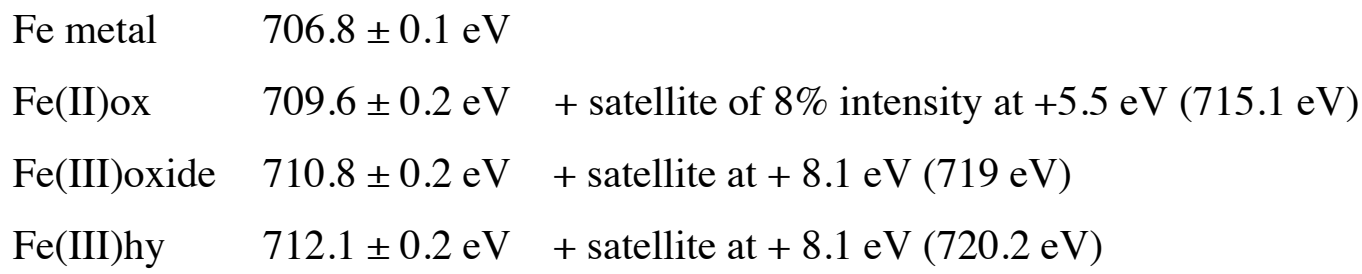

Apart from the binding energy values, the presence of satellites is considered a good "fingerprint" in order to identify the main oxidation state: a satellite at ca. $720 \mathrm{eV}$ indicates that mainly $\mathrm{Fe}(\mathrm{III})$ compounds are present.

The curve-fitting parameters for the individual compounds have to be based on standards [26]. The signal of metallic iron has not a pure gaussian/lorentzian shape but an asymmetric tail function towards higher binding energies. Neglecting this may lead to an overestimation of the signals of iron oxides and thus to erroneous results. Note that the shape, especially the width of the peaks (FWHM), also depends on the type of instrument used and on its settings (especially the pass energy). So a given set of parameters used on one instrument cannot be simply transferred to another one.

Based on the Fe2p3/2 spectra, the Fe(II) and Fe(III) oxy-hydroxide content in the passive films on iron and stainless steels can be determined. The first surface analytical study on iron in $0.1 \mathrm{~N} \mathrm{NaOH}$ [23] showed a gradual change of $\mathrm{Fe}^{2+}$ and $\mathrm{Fe}^{3+}$ in the passive film with increasing potential (Fig. 5a): at more positive potentials the passive film is composed mainly of Fe(III) compounds and the Fe(II) content diminishes. The results obtained by Rossi and coauthors [7,9] fit very well in this picture: increasing exposure time of steel samples at the OCP lead to an increase of the Fe(III) components in the passive film; the same dependence on potential as reported by [23] is found (Fig. 5b). It is worth to note that a similar time and potential dependence of the $\mathrm{Fe}(\mathrm{II})$ and $\mathrm{Fe}(\mathrm{III})$ compounds in the passive film was found also for stainless steels exposed to alkaline solutions $[17,28]$. Note that the $\mathrm{Fe}(\mathrm{II})$ content in the 
passive film at potentials immediately after immersion (-0.6 V SCE) corresponds to about $40 \%$ of the total iron oxide (Fig. $5 a)$.
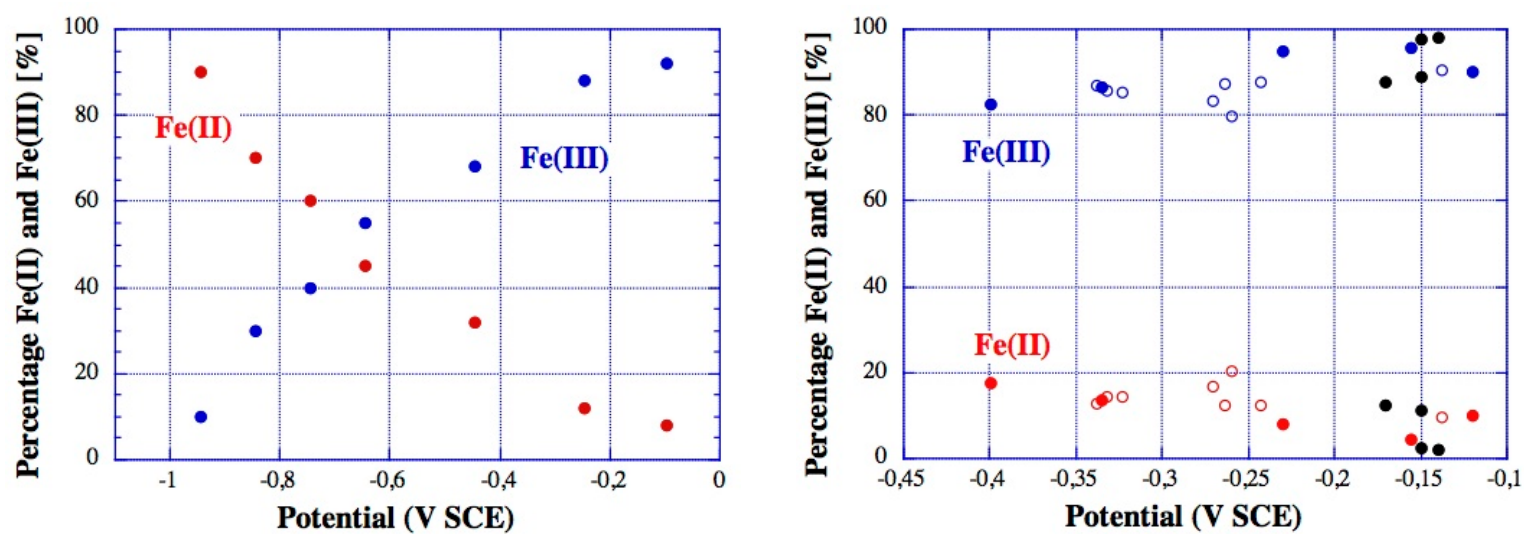

Figure 5: Different oxidation states of iron versus OCP. a) work from Strehblow and coauthors [23], b) work from Rossi and co-authors [7, 9]. Open circles: iron exposed to $0.1 \mathrm{~N}$ $\mathrm{NaOH}$, different times. Black points: bulk iron oxides exposed to $0.1 \mathrm{~N} \mathrm{NaOH}$.

\section{Quantitative XPS analysis of passive films on iron and stainless steels}

From the peak areas determined in the curve fitting procedure (Fig. 4) the concentrations of the different species can be calculated. The quantitative analysis has to take into account the attenuation of the photo-electrons, the transmission function of the analyser and the sensitivity factors of the different elements. For layered systems with a thin oxide film on the metallic substrate also the origin of the photo-electrons has to be considered. As approach for the calculation procedure the three-layer model was proposed [29] and adapted by the present authors to a broad variety of thin film systems, including the passivity of iron and stainless steels in alkaline solutions [30].

The three-layer model makes the assumption of three layers, homogeneous in thickness and composition: the contamination layer on top, the oxy-hydroxide layer and the metallic substrate (Fig. 6). With one single XPS experiment the thickness and composition of these three layers can be calculated. 

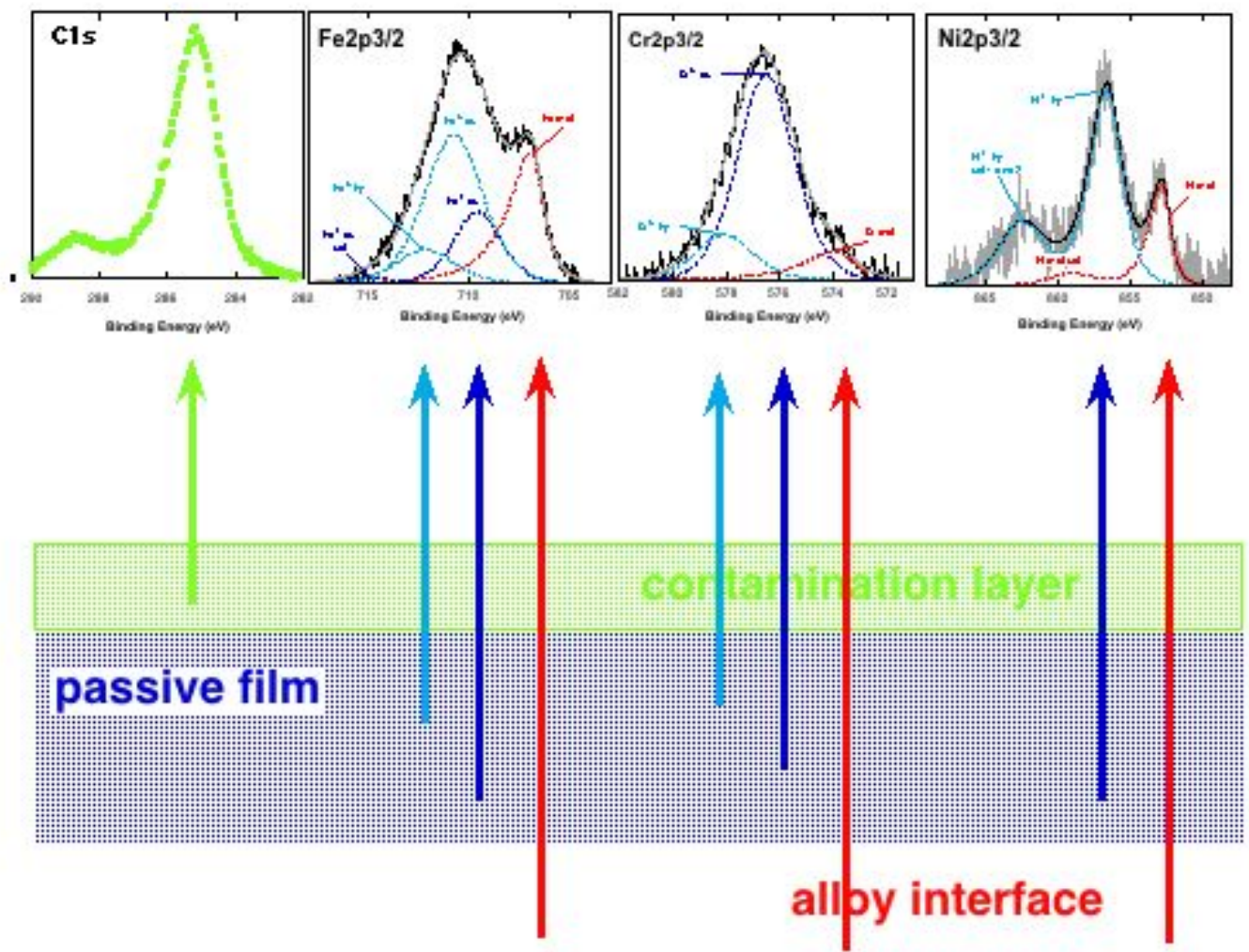

Figure 6: Three-layer model with contamination layer, passive film and alloy interface and the schematic representation of photo-electrons emitted by the different elements from the different layers

For the stainless steels studied the results of the evolution of the passive film composition with time of immersion in alkaline solution is shown in Figure 7. As a general trend a significant enrichment of chromium oxy-hydroxide can be observed, the content of oxidized iron decreased with time of immersion. The austenitic stainless steel shows up to $20 \%$ nickel oxy-hydroxide in the film.
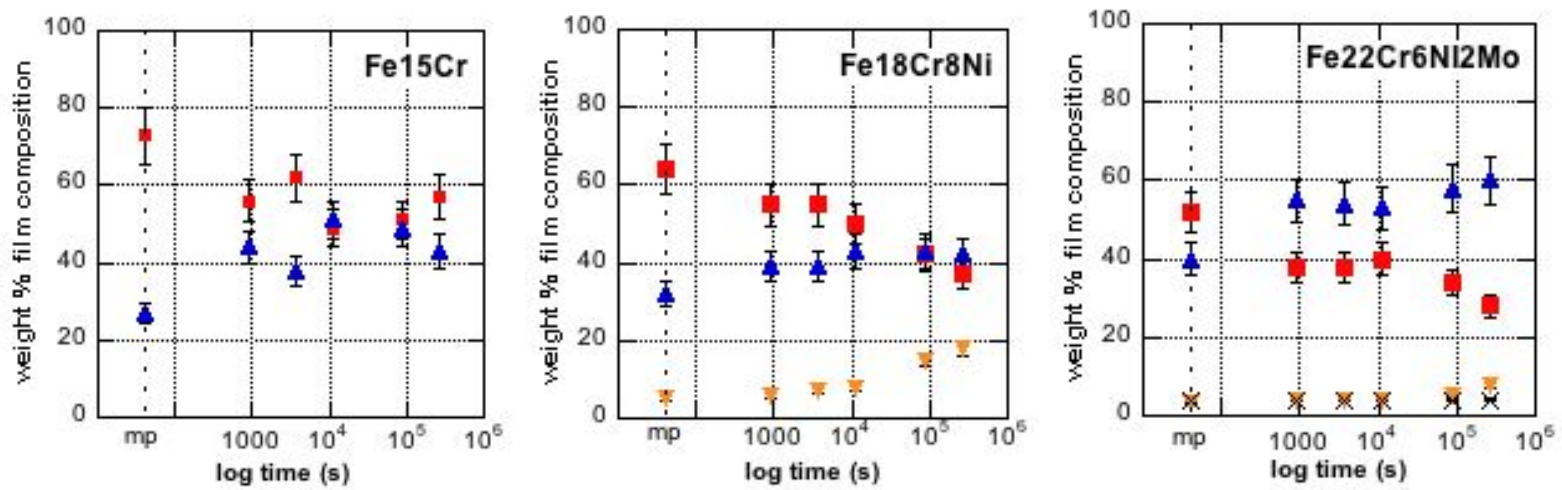
Figure 7: Composition of the passive film as a function of the immersion time in $0.1 \mathrm{~N} \mathrm{NaOH}$ solution. Data from [17]

The composition of the alloy beneath the passive film (interface) was calculated with the three-layer model (Table 1). The composition of the interface is different from the bulk composition of the alloy. The two nickel-containing stainless steels show a marked enrichment of nickel at the interface up to 38\% (austenitic steel) and 27\% (duplex). This corresponds to an enrichment factor of about four referred to the bulk composition. Also molybdenum gets enriched whereas chromium is depleted at the interface to $12 \%$ and $10 \%$ respectively (Table 1).

Table 1: Average composition of the alloy beneath the passive film (interface) after immersion for $24 \mathrm{~h}$ in alkaline solutions (data from [17, 28, 39])

\begin{tabular}{|l|l|l|l|l|l|}
\hline Alloy & Fe met & Cr met & Ni met & Mo met & Mn met \\
\hline Fe10Cr & $93(4)$ & $7(2)$ & - & - & - \\
\hline Fe15Cr & $86(8)$ & $14(2)$ & - & - & - \\
\hline Fe18Cr8Ni & $50(3)$ & $12(2)$ & $38(3)$ & - & - \\
\hline Fe20Cr6Ni2Mo & $57(4)$ & $10(2)$ & $27(3)$ & $6(1)$ & - \\
\hline Fe18Cr18Mn2Mo & $73(3)$ & $15(2)$ & - & $2(0.5)$ & $9(2)$ \\
\hline
\end{tabular}




\section{Stability of steel and stainless steel in alkaline media}

The protective properties of the passive films on the reinforcing steel are of great importance for the resistance against chloride induced localized corrosion and thus for the durability of reinforced concrete structures. Formation of the passive film leads to a decrease in corrosion rate with time reaching values $<0.1 \mu \mathrm{m} /$ year and virtually no corrosion is occurring $[6,10$, $13,14]$. Although a protective passive film starts to form soon after exposure of the steels to alkaline solutions (Fig. 1, Fig. 2), the quality and stability of the film depends on the exposure duration and the composition of the solution $[3,4,31]$ - thus on the ageing of the passive films. Ageing has beneficial effects for the long-term durability and resistance to pitting corrosion of steel in concrete that can be related to changes in the ionic or electronic defects of the passive films and - for stainless steels - changes in thickness and chemical composition of the passive films.

\section{Ageing of the passive films - change in defect concentration}

The passive film formation and stability of iron or black steel in alkaline media has been studied with respect to the presence of defects in the film and the film transformation from a magnetite $\mathrm{Fe}_{3} \mathrm{O}_{4}$ film with $50 \%$ of $\mathrm{Fe}$ (II) ions to a maghemite $\mathrm{Fe}_{2} \mathrm{O}_{3}$ film with only $\mathrm{Fe}$ (III) ions $[4,10,21,32]$ according to the reaction

$$
2 \mathrm{Fe}_{3} \mathrm{O}_{4}+2 \mathrm{OH}^{-}=3 \mathrm{Fe}_{2} \mathrm{O}_{3}+\mathrm{H}_{2} \mathrm{O}+2 \mathrm{e}^{-}
$$

This reaction is reversible, thus it can contribute to film growth in the anodic direction [25] and to film dissolution in the cathodic direction. In the oxidation direction the reaction is accompanied by the uptake of one oxygen atom into the lattice. The experimental data collected from literature confirm this film transformation (Fig. 8): the amount of Fe(II) in the passive film decreases with prolonged immersion, thus with increasing OCP $[9,23,32]$. The same trend has been found with EIS studies where the capacitance $\mathrm{Q}_{\mathrm{F}}$ of film formation and the conductivity of the passive layer decreased with increasing OCP [10]. A lower electronic conductivity was also reported [16].

Combining finally the data on the corrosion rate (Fig. 3) with the percentage of Fe(II) defects in the film at the different OCP (Fig. 8a), a linear relation can be found that links the decreasing $\mathrm{i}_{\text {corr }}$ (for passive steel the passive current density) with the decreasing percentage of Fe(II) ions in the film (Fig. 8b). Regarding the bi-layer structure of the passive film with an 
inner oxide layer and an outer hydroxide film [18 - 22], such a marked decrease in the passive current density has to be associated to a reduction in the Fe(II) content (electronic properties) in the inner barrier layer and not only to a thickening of the outer Fe(III) hydroxide layer.
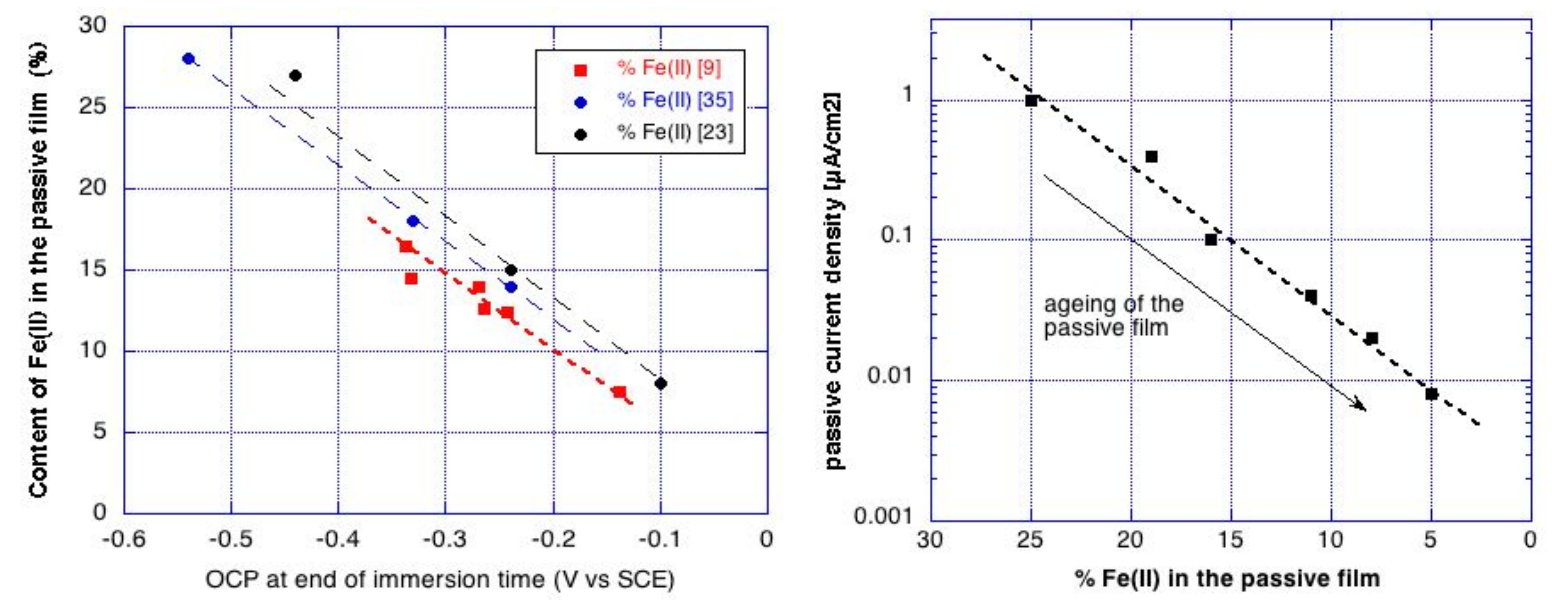

Figure 8: Passive films formed spontaneously by immersion of iron and black steel in alkaline solutions: a) Percentage of the Fe(II) content in the passive film vs the $\mathrm{OCP}, \mathrm{b}$ ) Passive film dissolution rate vs the $\mathrm{Fe}(\mathrm{II})$ content in the passive film

Ageing of the passive films - change in film composition of stainless steels

Starting from a surface film of the mechanically polished alloys rich in iron oxide, the passive films formed are progressively enriched in chromium oxy-hydroxide (figure 7) on ironchromium alloys and stainless steels. The chromium oxide content ranges between $45 \%$ (DIN 1.4301) and 60\% (DIN 1.4462) after 3 days of immersion. Progressive increase was also found for the amount of oxidized nickel in the passive films (figure $7 \mathrm{~b}, \mathrm{c}$ ): in the DIN 1.4301 with $10 \%$ of nickel in the bulk $20 \%$ of oxidized nickel is found in the passive film, favoured by the low solubility of $\mathrm{Ni}(\mathrm{OH})_{2}$ in alkaline media [33]). The passive film on the two stainless steels becomes more hydrated with longer immersion time [17]. This can be mainly related to the increase of the $\mathrm{Ni}(\mathrm{OH})_{2}$ and of the other hydroxide components in the film. In consequence, the passive films get progressively depleted in oxidized iron.

The $\mathrm{Fe}(\mathrm{II}) / \mathrm{Fe}(\mathrm{III})$ ratio in the passive films of stainless steels (with a content of only $40 \%$ of oxidized iron) is changing with ageing. The available data show that the $\mathrm{Fe}(\mathrm{II})$ percentage is decreasing with prolonged immersion time for Fe15Cr, Fe18Cr8Ni, Fe20Cr6Ni2Mo and also for Fe18Cr18Mn2Mo steels $[17,28]$ reaching after 1 day approx. $10 \%$ of the total oxidized iron, in good agreement with data on iron or black steel $[9,23,32]$. Together with the low 
content of oxidized iron the total amount of $\mathrm{Fe}(\mathrm{II})$ ions in the passive film decreases to about $3-4 \%$ only.

\section{Ageing of the passive film - Resistance to pitting corrosion}

The passive state of steel in alkaline environments (of particular importance concrete) remains stable for a very long time until chloride ions reach the steel surface. Several models exist for the chloride-induced depassivation of the steel, among them a change of the oxidation state of the inner part of the passive film [8,34] leading to breakdown of the film. Prolonged immersion (ageing) of black steel in alkaline solutions results in a significant decrease of the $\mathrm{Fe}$ (II) defects (Fig. 8) and in a marked increase in the pitting potential [35]; after $24 \mathrm{~h}$ of immersion of the steel in synthetic pore solution ( $\mathrm{pH}$ 13.2) despite a $\mathrm{NaCl}$ concentration of 1 $\mathrm{M}$ pitting was suppressed. Other influencing factors such as the metallic substrate, the presence of inclusions and of other possible local initiation sites are not included in this model.

Literature agrees that aging of the passive film of $\mathrm{FeCr}$ alloys and stainless steels improves the resistance to pitting $[36,37,38]$, this was mainly attributed to the enhancement of the chromium oxide content at the film/alloy interface or the decrease of defects in the passive film (Fig. 8). In addition, the role of the interface beneath the alloys was pointed out as important parameter $[17,28,39,40]$. As shown in Table 1 nickel containing stainless steels show a marked enrichment of the (more noble) alloying element nickel beneath the passive film. Once chloride ions have destroyed the passive film the aggressive ions face an alloy that is more a nickel-base alloy than a stainless steel and the resistance to pitting corrosion is much higher [40], probably due to a easier pit repassivation.

As initiation of localized corrosion is a stochastic phenomenon, the presence of a "more protective" passive film might not even be directly linked to the pitting resistance. 


\section{Comprehensive picture of passive films on iron in alkaline solutions}

Summarising the results from XPS surface analytical studies [7, 9, 11, 23, 31], in-situ Raman spectroscopy [20 - 22] and impedance spectroscopy studies [10, 21, 32], a quite consistent picture of the surface of iron and black steel in alkaline media can be proposed (Fig. 9): at low potentials mainly magnetite $\left(\mathrm{Fe}_{3} \mathrm{O}_{4}, \mathrm{Fe}\right.$ (II) to $\mathrm{Fe}(\mathrm{III})$ ratio $\left.1: 1\right)$ is found. With increasingly more positive potential (either impressed potentiostatically or from natural immersion and ageing at the open circuit potential) the oxide film thickens and gradually transforms to a $\alpha-$ $\mathrm{FeOOH}$ and $\mathrm{Fe}_{2} \mathrm{O}_{3}$ and the $\mathrm{Fe}(\mathrm{II})$ content practically disappears (fig. 9). This decrease in the defect density improves the quality of the passive film (decreasing passive current density, Fig. 8) and enhances the resistance to chloride induced pitting corrosion [35-38].
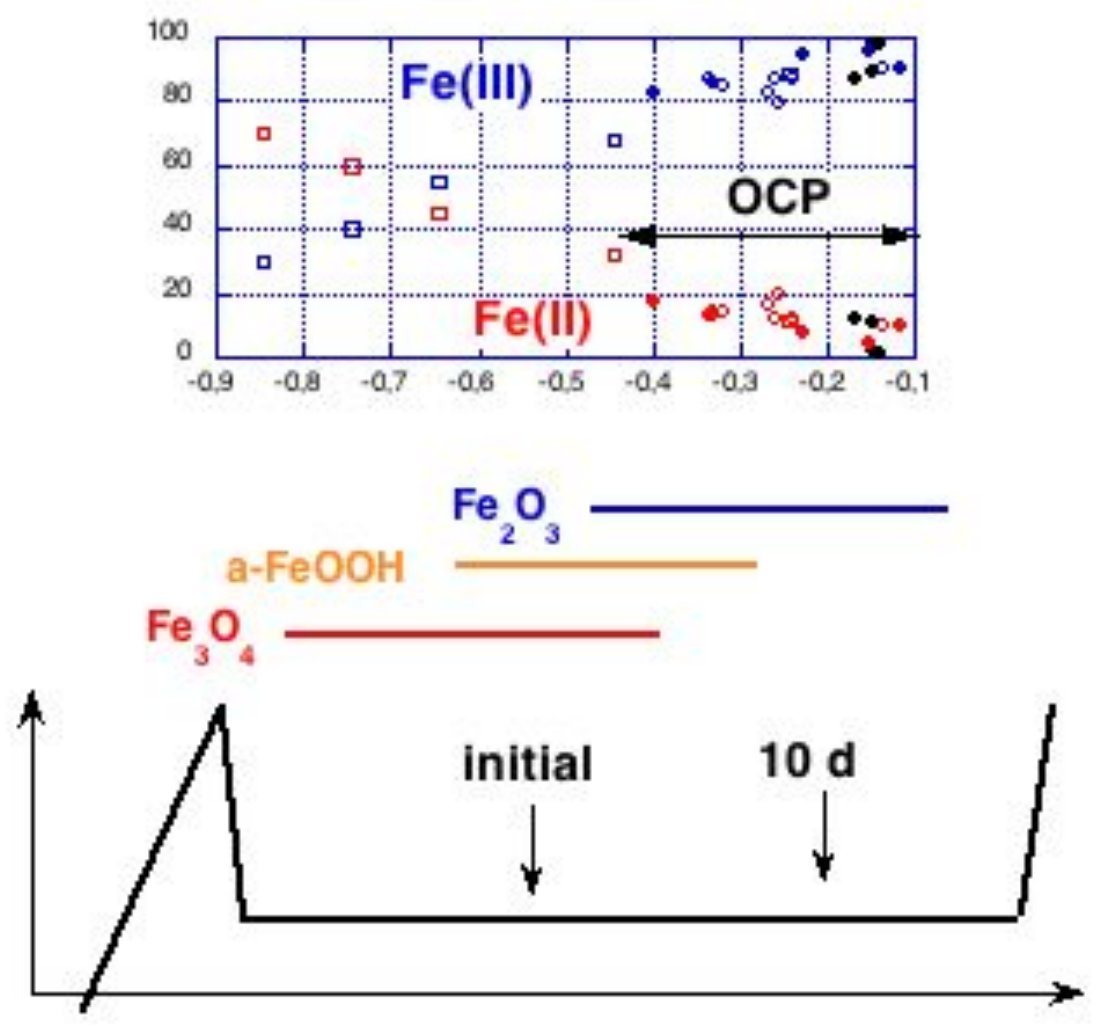

Potential

Figure 9: Proposal for a comprehensive picture of passive state of iron in alkaline solutions combining information from OCP, in-situ Raman spectroscopy and ex-situ XPS surface analysis

The question regarding the detailed structure of the passive film on iron in alkaline solutions is still under discussion. Generally the passive film on steel in alkaline solutions is described 
as a bi-layer structure with an inner barrier film and an outer less compact oxy-hydroxide film. Angle resolved XPS is - in principle - able to probe this passive film structure $[11,23$, 41], but simple intensity vs angle plots do not resolve the in-depth composition profile. This transfer from ARXPS to real in-depth profile can be performed with the Maximum Entropy Method (MEM) as has been reported for thin iron oxy-hydroxide films on mechanically polished iron [41] (Fig. 10). The transition from inner Fe(II) rich film to the outer Fe(III) rich film is gradual. Note however that a clear separation between an inner oxide film (comprising both $\mathrm{Fe}(\mathrm{II})$ and $\mathrm{Fe}(\mathrm{III})$ ) and an outer hydroxide film (with only $\mathrm{Fe}(\mathrm{III})$ ) is observed. On top of the oxide films always a hydrocarbon contamination layer is present.
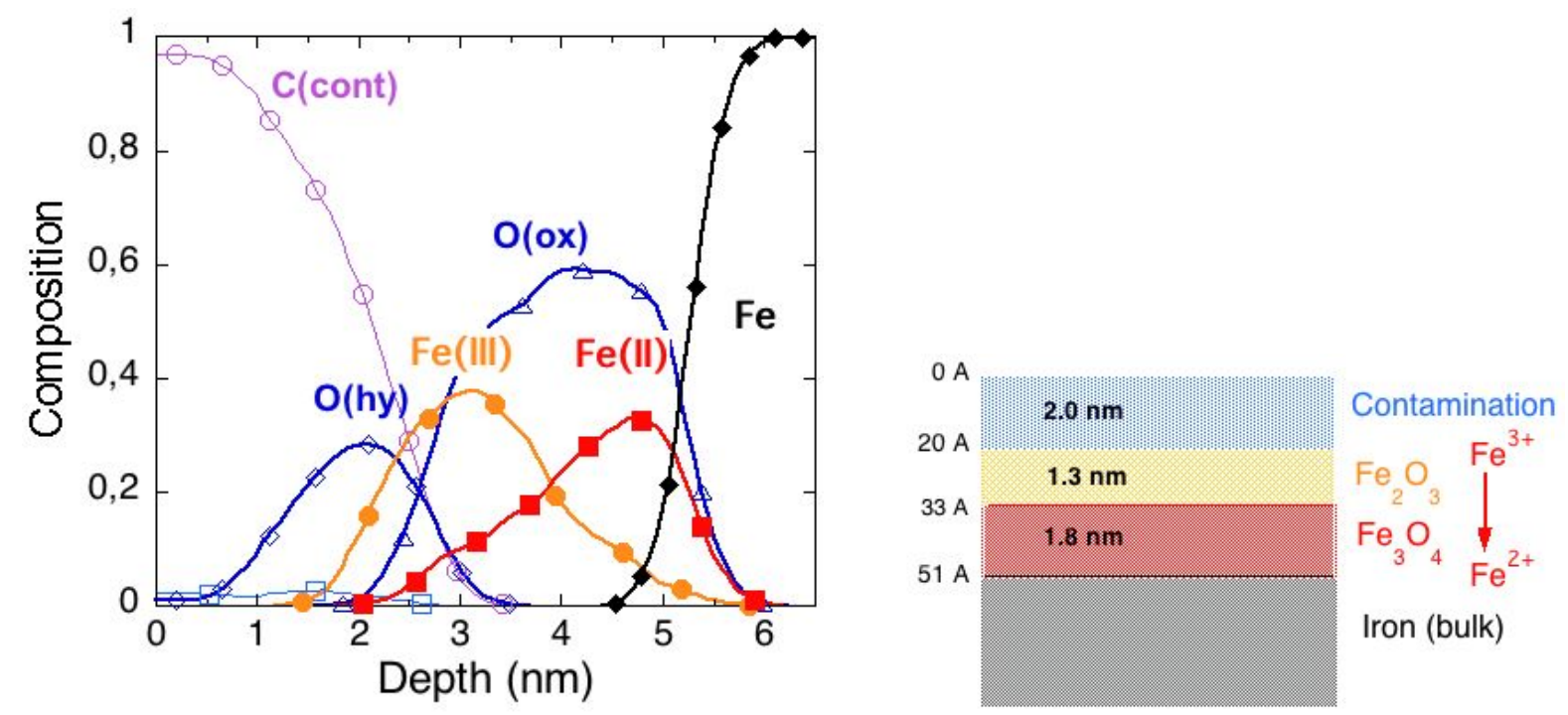

Figure 10: a) Layered structure of the passive film on iron with an inner $\mathrm{Fe}(\mathrm{II})$ rich and an outer Fe(III) rich part [41], b) model structure 


\section{Conclusions}

Results from electrochemical and surface analytical studies on the passive film growth on iron and stainless steels in alkaline solutions simulating concrete are presented and discussed in this work. The following conclusions can be drawn:

The passive film becomes more stable with prolonged immersion in alkaline solution (ageing), this is reflected in an increasing open circuit potential, an increasing polarization resistance or a decreasing passive current density.

Plotting the available data versus the open circuit potential, all data from electrochemical experiments are found on a common line in the log i vs OCP plot. Data from surface analytical experiments show a common, decreasing $\mathrm{Fe}(\mathrm{II})$ concentration with increasing OCP. Thus the decrease in the passive current density can be explained with a decrease in the defect concentration, more specifically the $\mathrm{Fe}(\mathrm{II})$ ion concentration in the passive film.

In general, passive films formed in conditions of prolonged ageing are more resistant to chloride induced localized corrosion, showing higher pitting potentials. This would indicate that less defective passive films are more resistant to pitting. As initiation of localized corrosion is a stochastic phenomenon, the link between presence of a "less defective" passive film and higher pitting resistance has still to be established. 


\section{Literature}

[1] M. Pourbaix, Lectures on Corrosion, Plenum Press New York (1973)

[2] L. Bertolini, B. Elsener, E. Redaelli, P. Pedeferri, R. Polder, Corrosion of Steel in Concrete - Second edition, WILEY (2013)

[3] U. Angst et al. M.R. Geiker, A. Michel, C. Gehlen, H. Wong, O. Burkan Isgor, B. Elsener, C.M. Hansson, R. Francois, K. Hornbostel, R. Polder, M. Cruz Alonso, M. Sanchez, M. Joao Correia, M. Criado, A. Sagüéz, N. Buenfeld, The steel - concrete interface, Materials and Structures, 50 (2017) 143

[4] M.C. Alonso, U. Angst, M. Sanchez and K.Y. Ann, Onset of chloride induced reinforcement corrosion, in: Handbook of Concrete Durability. Eds: Kim S-H, Ann KY. Middleton Publishing Inc., 2010, pp 1-48

[5] J. Flis, H.W. Pickering, K. Osseo-Asare, Interpretation of impedance data for reinforcing steel in alkaline solutions containing chlorides and acetates, Electrochimica Acta 43 (1998) 1921 - 1929.

[6] L. Li and A.A. Sagues, Chloride corrosion threshold of reinforcing steel in alkaline solutions - open circuit immersion tests, Corrosion 57 (2001) 19 - 28.

[7] A. Rossi, G. Puddu, B. Elsener, The surface of iron and Fe10Cr in alkaline media, Paper presented at Eurocorr 2001 (on CD).

[8] A. Poursaee, C.M. Hansson, Reinforcing steel passivation in mortar and pore solution, Cement and Concrete Research 37 (2007) 1127 - 1133.

[9] A. Rossi G. Puddu, B. Elsener, The surface of iron and Fe10Cr in alkaline media, in “Corrosion of Reinforcement in Concrete - Mechanisms, monitoring, inhibitors and rehabilitation techniques, ed. M. Raupach, B. Elsener, R. Polder and J. Mietz, EFC Publication no 38 (2007) $44-60$.

[10] M. Sanchez-Moreno, J. Gregori, C Alonso, J.J. Garcia-Joreno, H. Takenouti, F. Vicente, Electrochemical impedance spectroscopy for studying passive layers on steel rebars immersed in alkaline solutions simulating concrete pores, Electrochimica Acta 52 (2007) 7634 - 7641.

[11] P. Ghods, O.B. Isgor, G.A. McRae, G.P. Gu, Electrochemical investigation on chloride induced depassivation of black steel rebar under simulated in-service conditions, Corr. Sci. 52 (2010) 1649 - 1659. 
[12] S.M. Abd El Haleem, S. Abd, E. Abd El Aal, A. Diab, Environmental factors affecting the corrosion behavior of reinforcing steel II. Role of some anions in the initiation and inhibition of pitting corrosion of steel in $\mathrm{Ca}(\mathrm{OH})_{2}$ solutions, Corr. Sci 52 (2010) 292 302

[13] A. Poursaee, Corrosion of steel bars in saturated $\mathrm{Ca}(\mathrm{OH})_{2}$ and concrete pore solution, Concrete Research Letters 1 (2010) 90 - 97.

[14] E. Volpi, E. Olietti, M. Stefanoni, S.P. Trasatti, Electrochemical characterization of mild steel in alkaline solutions simulating concrete environment, J. Electroanal. Chem. 736 (2015) $38-46$.

[15] Yu-Min Chen, M. Orazem, Impedance analysis of ASTM A416 tendon steel corrosion in alkaline simulated pore solution, Corr. Sci. 104 (2016) 26 - 35.

[16] J. Williamson and O.B. Isgor, The effect of simulated concrete pore solution composition and chlorides on the electronic properties of passive films on carbon steel rebars, Corr. Sci. 106 (2016) 82 - 95.

[17] D. Addari, B. Elsener, A. Rossi, Electrochemistry and Surface Chemistry of Stainless Steels in alkaline Solutions, Electrochimica Acta 53 (2008) 8078 - 8086

[18] R.S. Schrebler Guzman, J.R. Vilche, A.J. Arvia, The potentiodynamic behaviour of iron in alkaline solutions, Electrochim. Acta 24 (1979) 395.

[19] J. Flis, H. Oranowska, Z. Szklarska-Smialowska, Corr. Sci. 30 (1990) 1085.

[20] A. Hugot-Le Goff, J. Flis, N. Boucherit, S. Joiret, J. Wilinski, Use of Raman spectroscopy and rotating split ring disk electrode for identification of surface layers on iron in $1 \mathrm{M} \mathrm{NaOH}$, J. Electrochem. Soc. 137 (1990) 2684 - 2690

[21] S. Joiret, M. Keddam, X.R. Nóvoa, M.C. Pérez, C. Rangel, H. Takenouti, Use of EIS, ring-disk electrode, EQCM and Raman spectroscopy to study the film of oxides formed on iron in $1 \mathrm{M} \mathrm{NaOH}$, Cem. Conc. Comp. 24 (2002) 7 - 15

[22] S. Joiret, M. Keddam, H. Perrot, H. Takenouti, X.R. Nóvoa, M.C. Pérez, Anodic Behaviour of Fe in $1 \mathrm{M} \mathrm{NaOH}$ in the presence of $\mathrm{Cl}^{-}$and $\mathrm{NO}_{2}^{-}$, Proc. VIII ${ }^{\text {th }}$ Symposium Passivity of Metals and Semiconductors, M.B. Ives, J.L. Luo, J.R. Rodda eds., Electrochemistry Proceedings Volume 99-42, The Electrochemical Society, Pennington NY (2001) p. 799.

[23] S. Haupt, H.H. Strehblow, Corrosion, Layer Formation, and Oxide Reduction of Passive Iron in Alkaline Solutions: A Combined Electrochemical and Surface Analytical Study, Langmuir 3 (1987) 873. 
[24] S. Haupt, H.H. Strehblow, Combined electrochemical and surface analytical investigations of the formation of passive layers, Corr. Sci. 29 (1989) 163

[25] P. Schmutz, D. Landolt, In-situ microgravimetric studies of passive alloys: potential sweep and potential step experiments with $\mathrm{Fe}-25 \mathrm{Cr}$ and $\mathrm{Fe}-17 \mathrm{Cr}-33 \mathrm{Mo}$ in alkaline solutions, Corr. Sci. 41 (1999) 2143.

[26] Practical Surface Analysis: Vol. 1 Auger and X-ray Photoelectron Spectroscopy, eds. D. Briggs and M.P. Seah, Second edition, WILEY 1996

[27] P.M.A. Sherwood, in [26] Appendix 3

[28] B. Elsener, D. Addari, S. Coray, A. Rossi, Stainless steel reinforcing bars - reason for their high pitting resistance, Materials and Corrosion 62 (2011) 111

[29] K. Asami and K. Hashimoto, An XPS study on the surface of Fe-Cr, Fe-Ni and Fe-Co alloys after mechanical polishing, Corr. Sci. 24 (1984) 83

[30] A. Rossi, B. Elsener, XPS analysis of passive films on the amorphous alloy $\mathrm{Fe}_{70} \mathrm{Cr}_{10} \mathrm{P}_{13} \mathrm{C}_{7}$ : effect of the applied potential, Surf. Interface Anal. 18 (1992) 499

[31] P. Ghods, O.B. Isgor, G. McRae, T. Miller, The effect of concrete pore solution composition on the quality of passive oxide films on black steel reinforcement, Cem. Concr. Comp. 31 (2009) 2 - 11

[32] M. Sanchéz-Moreno, H. Takenouti, J.J. Garcia-Jareno, F. Vicente, C. Alonso, A theoretical approach of impedance spectroscopy during the passivation of steel in alkaline media, Electrochim. Acta 54 (2009) 7222 - 7226

[33] Solubility of $\mathrm{Ni}(\mathrm{OH})_{2}$, CRC Handbook of Chemistry and Physics, 75th edition (1994), p. $4-78$

[34] P. Ghods, O. Burkan Isgor, J.R. Brown, D. Kingston, XPS depth profiling study on the passive oxide film of carbon steel in saturated calcium hydroxide solution and the effect of chloride on the film properties, Applied Surface Science, 257 (2011) 4669-4677

[35] S. Jäggi, B. Elsener, H. Böhni, Oxygen reduction on mild steel and stainless steel in alkaline solutions, in "Corrosion of Reinforcement in Concrete: Corrosion Mechanisms and Corrosion Protection", eds. J. Mietz, R. Polder and B. Elsener, EFC Publications Number 31, published by IOM Communications (2000) p. 3 - 12

[36] W.P. Yang, D. Costa, P. Marcus, Chemical Composition, Chemical States, and Resistance to Localized Corrosion of Passive Films on an $\mathrm{Fe}-17 \% \mathrm{Cr}$ Alloy, J. Electrochem. Soc. 141 (1994) $111-116$ 
[37] B. Baroux, The pitting corrosion of stainless steels (further insights), in "Corrosion mechanisms in theory and practice”, ed. P. Marcus and J. Oudar, Marcel Dekker Inc. NY (1995) chapter 9 p 265 - 309

[38] D.D. McDonald in Critical factors of localised corrosion, G.S. Frankel and R.C. Newman eds. Proc. Vol. 92-9, The Electrochemical Society, Pennington NJ (1992).

[39] A. Rossi, B. Elsener, Role of the interface oxide film/alloy composition and stability of stainless steels, Materials and Corrosion 63 (2012) 1188 - 1193

[40] B. Elsener, D. Addari, S. Coray, A. Rossi, Stainless steel reinforcing bars - reasons for their high pitting resistance, Materials and Corrosion 61 (2010)

[41] M. Olla, G. Navarra, B. Elsener and A. Rossi, Nondestructive in-depth composition profile of oxy-hydroxide nanolayers on iron surfaces from ARXPS measurements, Surf. Interface Anal. 38 (2006) 964 - 974 